\title{
MITOLOGIA DO MUNDO VEGETAL GRECO-ROMANO: ALGUNS EXEMPLOS PARTICULARES
}

\author{
Prof. Me. Marco Antonio Abrantes de Barros Godoi (UERJ)
}

RESUMO: Desde os tempos primitivos, o animismo vem sendo uma característica universal da visão que o ser humano tem sobre a sua experiência com seu ambiente, sendo uma perspectiva holística do universo, este ser humano encara-o como um universo vivo, seja uma pedra, seja um rio, ou a vegetação ao redor, todos possuem um espírito que se manifesta e se conecta com todos ao redor. A partir desta visão de mundo primevo, as sociedades posteriores construíram uma visão do mundo vegetal complexa que leva a representações de cada elemento da natureza. Aqui pretendemos observar, na primeira parte um aspecto geral desta perspectiva sobre uma visão do mito e da forma como o homem veio construindo esta percepção do mundo vegetal e seu elo com sua vida. Na segunda parte estudaremos algumas particularidades do mito do carvalho, do narciso, da oliveira e da videira.

PALAVRAS-CHAVE: Vegetação, Mito, Religião.

\section{MYTHOLOGY OF THE GRECO-ROMAN VEGETABLE WORLD: SOME PARTICULAR EXAMPLES}

\begin{abstract}
Since primitive times, animism has been a universal feature of the view that human beings have about their experience with their environment, being a holistic perspective of the universe, this human being sees it as a living universe, be it a stone, be it a river, or the surrounding vegetation, everyone has a spirit that manifests and connects with everyone around. From this primeval world view, later societies built a complex plant world view that leads to representations of each element of nature. Here we intend to observe, in the first part, a general aspect of this perspective on a vision of the myth and of the way man came to build this perception of the plant world and its link with his life. In the second part we will study some particularities of the myth of the oak, the narcissus, the olive and the vine.
\end{abstract}

KEYWORDS: Vegetation, Myth, Religion.

\section{Introdução:}


Desde as sociedades de caçadores, o ser humano vê e observa o processo de mudança no mundo vegetal, nas plantas, nas árvores, que, através das estações estas plantas e árvores sofrem processo de nascimento, amadurecimento, envelhecimento e morte, e a partir desta experiência, identifica o mesmo processo em sua própria existência, interpretando-as como uma manifestação de forças espirituais na natureza. $\mathrm{O}$ animismo, que é uma perspectiva do sagrado comum as mais diversas sociedades, vê e interpreta o mundo como uma anima mundi, isto é, tudo possui espírito e tudo é manifestação dos Deuses ou Deusas e tudo se interliga numa foça coletiva que traz e faz o mundo ser como ser. A compreensão desta relação entre as coisas é explicada pelos diversos mitos que permeiam a leitura e o discurso de como o mundo funciona.

Esta leitura simbólica do mundo vegetal correlaciona-se com a questão do processo de vida, amadurecimento, envelhecimento e morte do ser humano. O "mistério" da vegetação justifica o "mistério" da vida humana. Também sua interdependência; tanto que na economia da religião o ritual de oferenda aos Deuses e Deusas se faz por meio de vegetais enquanto no sacrifício se oferece animais.

No mundo vegetal, o mito também se faz por simbologias específicas que, devido a diversidade de vegetais e suas características, particularizam certos atributos que singularizam cada planta devido seus atributos, fazendo associações específicas devido estas características. Aqui particularmente estudaremos quatro singularidades, o Carvalho, representação do poder supremo divino, o Narciso, representação do processo de morte simbólica, e do mito do Narciso, a Oliveira, símbolo da Deusa Atená e da planta civilizatória, e seu oposto a Videira, símbolo de Dioniso e do transe.

\section{O Mito da Vegetação:}

Como foi dito anteriormente, o mundo vegetal relaciona-se com o processo de vida e morte, pois como os vegetais sofrem mudanças que vão, de acordo com as estações, do nascimento na primavera, ao amadurecimento no outono e à morte no inverno, este ciclo é infinito, assim como a vida humana também; a partir desta experiência o mito agrário coloca na sociedade antiga uma perspectiva de leitura do mundo sob o ponto de vista da circularidade, isto é, o mundo circula em torno de um processo de nascimentos e mortes. 
Com a descoberta da agricultura (9.000 a 7.000 A.E.C.), as relações e construções simbólicas sociais e mitológicas se transformam e reforçam esta visão cósmica do ciclo de vida e morte. A sobrevivência dos grupos sociais se tornam mais fixados no mundo vegetal do que na caça; o domínio do conhecimento do cultivo também fará uma divisão de trabalho entre o homem e à mulher, cabendo, essencialmente a esta o papel de controlar os meios de manutenção da subsistência do grupo, de conservação deles e ao homem o meio de circulação e extração destes meios. A mulher passa a ser e ter uma importância maior do que nas sociedade de caçadores em que ela era vista como uma pessoa em condição igual ao homem. Surgirão narrativas míticas, a partir desta circunstância em que a origem do conhecimento da agricultura se faz por meio de alguma divindade imolada, isto é alguma divindade é imolada para que o ser humano tenha o "fruto da terra"; O mito de Deméter que perde sua filha Perséfone para Hades é uma ilustração bem simbólica dessa "imolação".

A capacidade de a humanidade controlar o mundo vegetal de forma parcial, já que as técnicas agrícolas dependiam do clima, podendo sofrer as inconstâncias do mesmo, e assim o trabalho de um ano se perderia, proporcionavam uma leitura do universo como uma relação de equilíbrio tênue entre a vontade da divindade e a vontade do homem, sendo assim, Se criavam rituais propiciatórios para que a vontade dos Deuses se coadunassem com a dos homens. Como já foi dito anteriormente, o ritual da oferenda era um deles. Mas todo ritual é complementado com uma narrativa mítica, o ritual é um dos aspectos da religiosidade, para ela ser completa se precisa de um discurso mítico que justifique aquela cosmovisão e, particularmente o ritual, daí múltiplas narrativas míticas surgirão, por suas temáticas particulares ou genéricas; as particulares justificarão um ritual específico, as genéricas como o caso do rapto de Perséfone, justificarão a ideia religiosa. E, dentro dessa visão genérica, o mundo vegetal é justificado pelo drama mítico de uma Hierogamia, casamento entre o Deus do Céu e a Terra-Mãe, que implica na união sexual de ambos, também na implicação da morte e ressureição. Toda narrativa mítica associada aos cultos agrários tem por estrutura básica o movimento de morte e ressurreição, veja o mito supracitado de Deméter-Perséfone-Hades, ou o mito da vida de Dioniso. Agora iremos tratar das particularidades do mundo vegetal sobre como o Carvalho, o Narciso, a Oliveira e a Videira são interpretadas pelo discurso mítico. 


\section{O Carvalho:}

O carvalho é uma árvore sagrada para diversas religiões, se trata de uma árvore alta que, durante as tempestades costuma atrair o raio, por essa situação os antigos associaram esta árvore à divindade suprema do céu, Zeus (Júpiter) especificamente na religião greco-romana. $\mathrm{Na}$ antiga cidade grega de Dodona havia um carvalho de Zeus onde se consultava um oráculo, sua simbologia estava associada ao conceito de força, sendo assim, a clava de Hércules é feita de carvalho. Simbolizava também a solidez e a longevidade, atributos que também eram cobradas da justiça entre os homens, e Zeus era o Deus da justiça. Entre os romanos, gregos e celtas esta árvore representava o contacto entre os Deuses e a humanidade, a partir dele os Deuses se comunicavam com os homens, vide que, na religião judaica, foi por meio de um Carvalho que Jeová se comunicou com Abraão. Assim o carvalho é o eixo do mundo, pois é ele que faz os Deuses atuarem e se manifestarem entre os homens, para que haja harmonia no universo. Por fim, também segundo Plínio, o Velho, o termo que designa carvalho entre os celtas é dervo, que ele coloca como origem etimológica para o termo druida, sacerdote por excelência na religião celta.

\section{O Narciso:}

O narciso representa a planta que se associa aos cultos infernais por lembrar a morte, mas não a morte física, mas a morte como sono, momento de entorpecimento, pois sua etimologia se liga a palavra narké, associada a narcose. Era a planta utilizada para o culto de Deméter, em Eleusis. Por ser uma planta que se cria em ambientes bem húmidos e floresce na primavera, passou a simbolizar a água e aos ritmos sazonais, representando o ciclo de nascimento, vida e morte como falamos anteriormente, dando ênfase a questão da morte. Por isso foi com o perfume desta flor que Hades seduziu Perséfone e a raptou para o mundo dos mortos.

Esta planta também está associada a figura mitológica de Narciso, filho do Deus-rio Cesifo e da Ninfa Liríope, o jovem mais belo da Grécia. Narciso provocava a paixão entre as ninfas e as mulheres gregas, mas Narciso não correspondia aos desejos das moças e ninfas, a ponte de a ninfa Eco, definhar-se em paixão por ele e morrer transformando-se num rochedo que reproduzia os sons das pessoas, assim as ninfas pedem à Deusa Nemesis um castigo para Narciso, que o condena a amar um amor impossível. Narciso ao aproximar-se de uma fonte, ao ver sua própria imagem refletindo na água, se apaixona a ponto de não conseguir sair do local, morrendo no mesmo. Quando foram procurar o corpo de Narciso no 
local só viram uma flor amarela cujo centro era coberto por pétalas brancas, o narciso. Na modernidade o Narciso, personagem, deu origem ao conceito psicológico de narcisismo, isto é, a pessoa que ama somente a si, ou tem um conceito hiper valorativo de sua personalidade perante os outros.

\section{A Oliveira:}

A oliveira é uma árvore que tem importância econômica e social nas sociedades antigas do mediterrâneo, por isso ela é carregada de símbolos diversos, representando a paz entre os judeus, pois a pomba traz, para Noé, como fim do dilúvio, uma oliveira. Fecundidade também é um símbolo comum, pois ela traz riqueza para os seus criadores e comerciantes, pois ela era utilizada para temperar alimentos, sabão e combustível.

Na Grécia ela é consagrada à Deusa Atená, Deusa da inteligência e protetora do lado civilizatório da humanidade, sendo a oliveira o símbolo disto tudo, por ser um dos principais recursos empregados para diversas atividades humanas como disse anteriormente, como alimentação, higiene e energia. Na Grécia antiga as oliveiras eram proibidas de serem cortadas, a ponto de ser considerado um crime. Há não ser por alguma necessidade sagrada.

\section{A Videira:}

Tanto quanto a oliveira, a videira carregam em si diversos símbolos. Plantada em diversas culturas desde os egípcios até os romanos, ela simbolizou em diversas culturas o conhecimento da vida após a morte, simbolizando a consciência de que a alma permanece sobre a morte. No judaísmo simbolizava a árvore da vida do paraíso; no cristianismo simbolizava o sangue de Cristo e assim a ressureição. Na Grécia Antiga representava o símbolo maior do Deus Dioniso, representando também os mistérios da vida após a morte mais os renascimentos da divindade agrária (Dioniso, morre e renasce) e do ser humano. O processo do culto do Diniso com o emprego do vinho, leva a metáfora da pessoa se tornar outra por incorporar Dioniso, daí a origem do Teatro, cujos personagens são representação do outro por atores que não são estes outros.

O vinho desde a antiguidade ou era vermelho ou branco, por essa dupla qualidade o vinho simbolizava a união entre o Céu e a Terra; tratava-se da união entre o espírito e a matéria, sabedoria e paixão ao mesmo tempo.

\section{Considerações finais:}


Como podemos ver, o universo mítico simbólico do ser humano condiz com sua experiência vivida com o seu lugar e tempo, a realidade concreta influencia a forma como o homem interpreta o mundo, quanto mais antiga a vivência humana, mais próximo da natureza, mais anímica fica sua leitura do seu mundo ao redor. A particularidade da vida vegetal é vista como uma dádiva divina dos Deuses e Deusas para a vida e sobrevivência do homem, os vegetais, com o advento da agricultura torna a sociedade humana mais segmentada em atividades econômicas especializadas de acordo com o gênero (homem-provedor, mulher- criadora), assim o universo é ressignificado e novas simbologias são criadas a partir dessa nova vivência humana.

A realidade da natureza é representada por uma leitura cultural que se faz em cima do ciclo existência de nascimento-amadurecimento-envelhecimento e morte. O ciclo da natureza é o ciclo do homem, pois ambos fazem parte do mesmo ciclo e ambos estão inseridos no mesmo mundo e os Deuses e Deusas também fazem parte do mesmo ciclo, a diferença que os divinos são eternos em seu ser, enquanto o homem apaga seu ser a cada morte e forma outro ser a cada renascimento.

O pensamento mítico se faz nesta experiência no mundo vegetal como um processo de analogia entre os seres humanos e as plantas, mas cada planta carrega uma singularidade, uma característica idiossincrática, assim como as qualidades dos homens e de suas personalidades, embora façam parte de um todo, mas este todo não é absoluto, é relativo, isto é, é a relação em que há cada qualidade atribui a si e no conjunto do mundo. Assim como a natureza funciona em rede de combinações, as qualidades humanas também funcionam assim. Trata-se de relações complementares que produzem um efeito no mundo. O Mundo do Mito antigo é o mundo das forças da natureza interagindo e o homem é fruto disto, não ao contrário.

\section{Referências Bibliográficas:}

BRANDÃO, Junito de Sousa. Dicionário Mítico-Etimológico: Mitologia Grega. Petrópolis: Vozes, 2a . ed. 1997.

Cassirer, Ernst. A Filosofia das Formas Simbólicas: II- O Pensamento Mítico. São Paulo: Martins Fontes. 2004. 
CHEVALIER, Jean \& GHEERBRANT, Alain. Dicionário de Símbolos. Rio de Janeiro: José Olympio, 9a .ed. s.d.

ELIADE, Mircea. História das Crenças e das Idéias Religiosas I: Da Idade da Pedra aos Mistérios de Elêusis. Rio de Janeiro: Zahar, 2010

GRIMAL,Pierre. Dicionário da Mitologia Grega e Romana. Carnaxide: DIFEL, $2^{\mathrm{a}}$ ed. S.d. 